\title{
INTELIGÊNCIA ARTIFICIAL E DECISÃO JUDICIAL: (IM)POSSIBILIDADE DO USO DE MÁQUINAS NO PROCESSO DE TOMADA DE DECISÃO
}

\author{
Ana Débora Rocha Sales ${ }^{1}$ \\ Carlos Marden Cabral Coutinho ${ }^{2}$ \\ Leticia Vasconcelos Paraiso ${ }^{3}$
}

\section{Resumo}

A promessa é agilizar e descongestionar fila dos processos judiciais, tendo em vista que as máquinas de inteligência artificial podem executar tarefas com eficácia e celeridade superior. O problema reside na investida de implementação da inteligência artificial no processo de tomada de decisão. O presente trabalho tem objetivo analisar quais são ressalvas para o uso das máquinas com função total ou parcial de deferir decisões no âmbito judicial. A metodologia foi o dedutivo, de cunho bibliográfico, com materiais teóricos, bem como documentos normativos. Concluímos que não é possível a inclusão das máquinas em todas as etapas em uma decisão judicial.

Palavras-chave: Direito; Vieses Algorítmicos; Inteligência Artificial; Tomada de Decisão; Machine Learning.

\section{ARTIFICIAL INTELLIGENCE AND JUDICIAL DECISION: IMPOSSIBILITY OF USING MACHINES IN THE JUDICIAL DECISION MAKING PROCESS}

\begin{abstract}
The promise is to streamline and clear the queue of legal proceedings, considering that artificial intelligence machines can perform tasks with superior efficiency and speed. The problem lies in the onslaught of implementing artificial intelligence in the decision-making process. The present work aims to analyze which are reservations for the use of the machines with total or partial function of granting decisions in the judicial scope. The methodology was deductive, of bibliographic nature, with theoretical materials, as well as normative documents. We conclude that it is not possible to include the machines at all stages in a court decision.

Keywords: Law; Algorithmic Biases; Artificial intelligence; Decision making; Machine Learning.

\section{INTRODUÇÃO}

\footnotetext{
${ }^{1}$ Doutoranda em Ciências Jurídicas pela Universidad del Museo Social Argentino - UMSA (2020- dias atuais). Mestranda em Direito pelo Centro Universitário Christus - Unichristus (2020- dias atuais), com bolsa parcial da CAPES. Pesquisadora na linha de Pesquisa de Epistemologia, Inteligência Artificial e Decisão Judicial do NUPID. Especialista em Direito Previdenciário pelo Centro Educacional Damásio de Jesus. (anadeboraadv@hotmail.com)

2 Procurador Federal. Especialista em Direito Processual Civil e Mestre em Ordem Jurídica Constitucional pela Universidade Federal do Ceará. Doutor em Direito Processual pela Pontifícia Universidade Católica de Minas Gerais. Estágio Pós-doutoral em Estado, Democracia e Constituição pela Universidade do Vale do Rio dos Sinos. Professor da Graduação e do Mestrado do Centro Universitário Christus - Unichristus. (carlosmardencc@hotmail.com)

3 Advogada. Mestranda em Direito pelo Centro Universitário Christus - Unichristus. leticiavasconcelosparaiso@hormail.com
} 
A inteligência artificial vem se tornando cada vez mais uma alternativa para os vários setores da sociedade. Seja na indústria, prestação de serviços, celebração de contratos ou na vida cotidiana, os softwares já são capazes de desempenhar funções semelhantes às de um ser humano. No direito, isso não é diferente, a imersão cada vez mais rápida das lawtechs e legaltechs no mundo jurídico é um reflexo da automatização desse campo.

Nos Estados Unidos, ferramentas que usam inteligência artificial já é uma realidade nos escritórios de advocacia e também nos tribunais. Os robôs Watson e Ross são exemplos de máquinas que, por meio de uma busca de dados, podem prever resultados de sentenças, interpretar a jurisprudências e criar documentos específicos. Os escritórios têm vislumbrado nesse tipo de tecnologia uma saída para agilizarem serviços burocráticos e repetitivos.

No Brasil também já é possível verificar esse tipo de tecnologia inserido âmbito do direito e do Poder Judiciário. Como exemplo, podemos citar a máquina batizada com o nome de Luzia, uma advogada robô projetada pela startup Legal Labs com a função de exercer com maior eficiência as execuções judiciais, além de possuir capacidade de analisar processos, verificar seu andamento e traçar rumos para sua resolução. Dra. luzia já tem um emprego garantido na procuradoria geral do Distrito Federal, sua função será descongestionar o grande volume de processos relacionados à arrecadação de impostos na capital do país. (Canal tech, 2017).

É inegável que a utilização de inteligência artificial como meio para resolução de litígios no Brasil, se constituiria uma revolução, visto que o país acumula um número expressivo de processos, segundo os dados do Conselho Nacional de Justiça, o ano de 2019 terminou com cerca de 77,1 milhões de processos não julgados. Na concepção Nunes e Viana (2018), é evidente que o uso de software é um aliado para o andamento de processos, pois podem compilar e selecionar dados com uma celeridade e eficácia surpreendente.

Contudo, já há uma investida por parte dos entusiastas da tecnologia e do direito no sentido de implantar essas máquinas com a função de decidir, ou seja, julgar os processos que chegam aos tribunais. Essa funcionalidade seria parte de um engenhoso processo de armazenamento de informações, articulado por algoritmos, os quais responderiam questões levantadas no âmbito de um processo judicial.

À primeira vista, a utilização dessa tecnologia pode ser considerada um método inquestionável, no que se refere às decisões proferidas, pois estariam livres de parcialidade e de equívocos, já que as máquinas são, cada vez mais, precisas e irrefutáveis. Porém, alguns 
juristas alertam sobre os riscos do uso acrítico da inteligência artificial como método de tomada de decisão. A tese sustentada por eles é que, as máquinas podem até ser naturalmente imparciais, mas podem carregar critérios subjetivos de interpretação, dos dados que as possibilitam funcionar.

Outra preocupação relacionada ao uso da inteligência artificial como mecanismo de tomada de decisão refere-se à opacidade dos métodos utilizados pelos algoritmos para proferirem seus resultados. Os procedimentos utilizados por essas máquinas ficam resguardados aos domínios de seus criadores e permanece uma incógnita para a maioria das pessoas.

Essas questões levantam uma problemática muito importante a ser refletida: as máquinas possuem a predisposição de proferir decisões calcadas em fundamentos válidos e livre de parcialidade? A fim de responder esse questionamento este estudo se compromete analisar alguns casos de máquinas com inteligência artificial já implementados com a atribuição total ou parcial de proferir decisões e a qualidade desses resultados à luz dos parâmetros legais. A intenção é verificar se os algoritmos são completamente capazes de determinar decisões judiciais válidas para os diferentes casos que se apresentam na realidade.

Para cumprir com os objetivos dessa pesquisa o trabalho será dividido em três partes. A primeira se constituirá nos apontamentos sobre a inteligência artificial e o processo de Marchine Learning (aprendizado das máquinas). A segunda parte refere-se ao estudo feito sobre a inserção da inteligência artificial no campo judicial, assim como uma abordagem dos viesses algorítmicos como eles podem desviar a imparcialidade dos mecanismos não humanos de inteligência. A terceira parte reflete sobre a opacidade dos procedimentos algoritmos de decisão e a fundamentação das decisões judiciais, preceito constitucional e regramento taxativo no Código do Processo Civil (CPC) e no Código do Processo Penal (CPP).

A metodologia aplicada nessa pesquisa foi à dedutiva, de cunho bibliográfico, onde foram utilizados materiais teóricos de livros, artigos, produções acadêmicas, bem como nos documentos normativos que dissertam sobre o tema deste trabalho.

\section{BREVES APONTAMENTO SOBRE INTELIGÊNCIA ARTIFICIAL E MACHINE LEARNING}


Há, indubitavelmente, um movimento irrefreável de imersão da tecnologia em todas às áreas da vida humana. No campo do direito, a entrada da tecnologia e a mudança nos paradigmas fez surgir à expressão "virada tecnológica no direito", a qual expressa, justamente, essa nova dinâmica que se impõe com o incremento de novas ferramentas no cotidiano das relações jurídicas.

Software, algoritmo e inteligência artificial são algumas das nomenclaturas que surgem com os novos ventos da tecnologia. Apesar de serem tratadas frequentemente como sinônimas, ambas possuem significados próprios, mas que se entrelaçam por ter uma estreita relação.

Inteligência artificial pode ser conceituada como sendo a capacidade de reproduzir em uma máquina as capacidades cognitivas de um ser humano. De acordo com Peixoto e Silva (2019, p. 20) "se refere à capacidade de reprodução artificial da capacidade de adquirir e aplicar diferentes habilidades e conhecimentos para solucionar dado problema, resolvendo-o, raciocinando e aprendendo com as situações".

As máquinas que utilizam inteligência artificial funcionam a partir de algoritmos. Por algoritmo entende-se como "um plano de ação pré-definido a ser seguido pelo computador, de maneira que a realização contínua de pequenas tarefas simples possibilitará a realização da tarefa solicitada sem novo dispêndio de trabalho humano" (LEONARDO; ESTEVÃO, 2020, p. 7). Em outras palavras, o algoritmo é o conjunto de passos usados para fazer uma tarefa específica, funciona como um bloco de informações que permitem que um dado equipamento realize suas funções. Esses algoritmos atuam de acordo com o programa ou aplicativo (software) que eles estão acoplados.

\footnotetext{
Um algoritmo não costuma ter vida própria e é útil quando encapsulado num programa que, combinando-o com outros algoritmos, permite o cumprimento de certa tarefa pela máquina. De programas fazem-se os sistemas que cabem, de uma maneira mais própria, no conceito de software. Portanto, algoritmo, programa, sistema e software denotam uma ordem ou sequência natural de organização de elementos pela qual se dá condições de utilidade a algoritmos. PEREIRA, 2017, p. 2017).
}

Em suma, a inteligência artificial é uma área de estudo da ciência da computação que se objetiva, mediante passos estruturados (algoritmos) de um determinado programa (software), "construir mecanismos e/ou dispositivos que simulem a capacidade do ser humano de aprender e resolver problemas, ou seja, de ser inteligente" (MELO, 2020). Esse aprendizado é nominado de "Marchine Learning”. 
As máquinas ${ }^{4}$, assim como os seres humanos, precisam passar por um processo de aprendizagem, para desenvolverem o conhecimento necessário para desenvolver uma função. Na ciência da computação, o chamado Machine Learning é o processo de programação que tem o objetivo de treinar as máquinas para que elas consigam dar uma resposta coerente ao comando realizado. É esse processo que dá a possibilidade de uma máquina adquirir a inteligência artificial.

O Machine Learning é um ramo da Inteligência Artificial, podendo dessa forma, ser classificado como uma subcategoria das Tecnologias Cognitivas. Este emprega uma variedade de técnicas estatísticas, probabilísticas e de otimização que permitem computadores a aprender e detectar padrões difíceis de discernir a partir de dados passados dos parâmetros analisados. (MATEUS; MENDOÇA, 2020, p. 37)

Em tradução livre, machine learning quer dizer aprendizado das máquinas, porém tem se atribuído a essa expressão um novo significado, qual seja, aprendizagem automática. Pois, os algoritmos podem ser construídos de maneira que possam aprender com sua própria experiência, dando resultados mais relevantes a cada comando realizado (VALENTINI, 2017).

O aprendizado das máquinas, de maneira simplificada, pode ocorrer de duas formas: supervisionado e não supervisionado. O aprendizado supervisionado como o nome pressupõe, exige a presença humana para que a máquina realize sua função. Nesse tipo de aprendizado os dados inseridos já estão catalogados de acordo com sua classificação, o papel da máquina é predizer rótulos desconhecidos. No aprendizado não supervisionado, os dados inseridos não possuem nenhum tipo de rótulo, os algoritmos da máquina irão procurar similaridades, padrões e a partir daí classificá-los (ELIAS, 2017).

Como exemplo de aprendizado supervisionado podemos citar o sistema de inteligência artificial implantado no Tribunal de Justiça de Minas Gerais. Radar, nome dado ao sistema, tem como principal função ler os processos e agrupá-los segundo sua similaridade. Com a identificação de processos repetitivos é feito a indexação automática e distribuição ao juiz natural da ação.

Dentre os critérios de pesquisa estão "as buscas por palavra-chave em geral, por data de distribuição, por órgão julgador, por magistrado, por parte, por advogado etc. e

\footnotetext{
${ }^{4}$ Muitas vezes é utilizado o termo "máquina" para referir-se à inteligência artificial, ressalta-se que, não necessariamente, esta se encontra em um corpo físico, sendo na prática um software que pode ser desenvolvido em uma parte física "hardware".
} 
por outras demandas que os julgadores necessitarem."91 Isso auxiliará os assessores dos desembargadores do Tribunal na elaboração de votos, uma vez que irá entregar pesquisas prontas de julgados, que poderão ser utilizados no voto. (MEDEIROS, 2019, p. 62)

Para Shalev-Schwartz e Ben-David, (2014) marchine learning não pode ser vista apenas como um método que dá à máquina a capacidade de realizar tarefas que poderiam ser desempenhadas por pessoas, mesmo que de forma demorada e repetitiva, mas, sim, utilizar as capacidades das máquinas como um aliado à inteligência humana. Como, por exemplo, fazer uma busca em um grande banco de dados detectando padrões sucintos que poderiam passar despercebidos aos olhos humanos.

Alpaydin (2014) considera que os padrões detectados por meio do marchine learning, são previsões alcançadas a partir de uma análise de fatos pretéritos, considerando que o futuro não poderá ser muito diferente do passado, em que deu origem ao dado em análise. Ou seja, a máquina é ensinada a detectar padrões, que podem ser padrões de comportamento, de opinião, de falas, que tendem se repetir futuramente se ocorrer o mesmo contexto em que estes foram construídas.

Deve-se ter em mente que as máquinas que usam inteligência artificial dependem de um mecanismo de entrada de dados (input), o sistema de dados programados, os algoritmos, devem ter pelo menos um meio para a entrada dos bits (informações em formato digital). Outrossim, é necessário um mecanismo de saída dos dados (output), os quais devem estar diretamente relacionados com o input. Um exemplo prático desse processo, é descrito por Valentini (2017, p. 42) "Por exemplo, um algoritmo de uma calculadora que receba as informações para somar 2+2 (input) irá retornar como resultado o número 4 (output)”.

O output decorre do input, sendo papel do algoritmo fornecer o retorno dos dados corretos a partir dos dados de entrada. Uma vez que o algoritmo não faz nenhum juízo de valor para além de sua programação, é necessário que a relação de "correção" entre o input e o output seja definida de modo preciso e sem ambiguidade. (VALENTINI, 2017, p. 42)

Isso significa dizer que toda ação realizada pelas máquinas de inteligência artificial depende dos modelos, os quais se referem a representações abstratas, simplificações do mundo real. "Ao criar um modelo, os programadores devem selecionar as informações que serão fornecidas ao sistema de IA e que serão utilizadas para prever soluções e/ou resultados futuros" (NUNES, 2018, p. 4).

Dierle Nunes (2018) ao dissertar sobre o aprendizado das máquinas, alerta para a ocorrência de "pontos cegos" na programação dos softwares. Pois ao compor um modelo o 
qual se baseará o sistema, o próprio programador, nesse caso uma pessoa, poderá imprimir naquelas informações prestadas os seus próprios objetivos, prioridades e concepções. Fazendo com que o programa (máquina) carregue marcas subjetivas do seu criador.

Esses blindspots (pontos cegos) podem ser irrelevantes para os resultados pretendidos pelos modelos. Por outro lado, podem ser ignoradas informações importantes para correta análise da situação, influenciando negativamente nas respostas dadas pelo sistema. (NUNES, 2018, p. 4)

O autor dá dois exemplos, o primeiro deles se refere a uma situação que os pontos cegos são irrelevantes ao propósito do sistema, que é o caso do GPS do Google, quando é feito uma busca o aplicativo só mostra vias de acesso como estradas, viadutos, tuneis, e desconsidera o restante de elementos que compõe a paisagem como os prédios, casas e outros edifícios. Esses são os pontos cegos do Google Maps e sua inexistência não atrapalha o desempenho do aplicativo. $O$ segundo exemplo se refere a um sistema de inteligência artificial, que por conta dos pontos cegos, podem chegar a resultados restritos. Como exemplifica Nunes (2018):

O modelo aplicado nas escolas de Washington, retornando para aquele exemplo, avalia os professores em grande parte com base nas notas de estudantes nos testes, mas ignora o quanto os professores engajam os estudantes, trabalham com habilidades específicas, lidam com a gestão da sala de aula ou ajudam seus alunos com problemas pessoais e familiares. O modelo é muito simples, sacrificando sua exatidão e diferentes percepções em prol da eficiência. No entanto, do ponto de vista dos administradores ele fornece uma ferramenta efetiva para investigar centenas de professores aparentemente com um baixo desempenho, mesmo que se corra o risco de interpretar incorretamente alguns deles. (NUNES, 2018, p. 5)

O que é possível verificar é que os pontos cegos, nem sempre serão essenciais, visto que não interferem no objetivo que é buscado ao utilizar um aplicativo ou um software, contudo, existem situações que para chegar a uma resposta contundente é necessário que seja levado em consideração todas as variáveis do processo. Como aponta o autor para o caso do aplicativo de avaliação dos docentes em Washington. O sistema de inteligência artificial foi desenvolvido para avaliar professores do sistema educacional do estado. Ele faz a avaliação levando em consideração exclusivamente as notas dos alunos, desconsiderando todo o contexto que direta ou indiretamente influencia no bom desempenho dos docentes em sala de aula.

Entretanto, não é coerente afirmar que o sistema de inteligência artificial é omisso por não analisar informações relevantes ao avaliar os professores, ao contrário, o sistema desenvolve suas atividades dentro das possibilidades que os dados oferecem. Se as informações prestadas se limitam às notas dos alunos, é a partir desses dados que é feito a avaliação, isso significa que os programadores (sistema educacional) acreditam que essa seja 
a mais eficaz maneira de avaliar um professor. Dessa forma, a resposta de uma máquina com inteligência artificial pode carregar subjetividades da sociedade, a qual teve os dados produzidos. É o que revela em pesquisa da Universidade de Oxford

o aprendizado de máquina pode reificar os padrões existentes de discriminação - se eles forem encontrados no conjunto de dados de treinamento, então, por design, um classificador irá reproduzi-los. Desta forma, as decisões tendenciosas são apresentadas como o resultado de um algoritmo "objetivo" (GOODMAN; FLAXMAN, 2017, p. 38).

Nota-se, portanto, que declarar que uma máquina com sistema de inteligência artificial pode dar resultados isentos e "desenviesado" seria inconsistente com a realidade, tendo em vista que a máquina produz suas respostas mediante os dados produzidos em um meio social, que, muitas vezes é permeada por desigualdades, discriminações e exclusões. Dessa forma, a qualidade dos dados se caracteriza como uma das variáveis que influenciará os resultados obtidos pelas máquinas.

É possível inferir também que o volume de informações não é o condicionante para uma resposta inequívoca pelas máquinas. O que realmente importa, nesse caso, é a qualidade das informações que é inserida no sistema de IA, pois dados enviesados ensinarão as máquinas uma realidade enviesada, o que culminará em resultados carregados de subjetividade que por vezes replicam preconceitos e discriminações.

\section{A INSERÇÃO DA INTELIGÊNCIA ARTIFICIAL NO PROCESSO DE TOMADA DE DECISÃO}

Sergio Rodas elenca três principais funções, nas quais as máquinas podem exercer dentro do Poder Judiciário. A primeira delas é análise de processos com a finalidade de classificar aqueles que tratam sobre as mesmas questões facilitando a resolução dos litígios pelos agentes do direito. A segunda atribuição refere-se à mineração de dados retirados de grande fonte de dados. Os algoritmos teriam a função de "extrair o essencial para o pesquisador de um grande volume de informação (documentos, processos, artigos técnicos e jornais, por exemplo)" (RODAS, 2020). E por fim, as máquinas podem atuar, na atividade judicante, ou seja, na deliberação de decisões de disputas judiciais.

As duas primeiras vertentes de atuação dos algoritmos, normalmente, não há discordância ou relutância de serem inseridas, tendo em vista que é um trabalho dispendioso e repetitivo, que pode ser otimizado com o auxílio da Inteligência artificial. Contudo, a vertente relacionada à possibilidade de as máquinas realizarem a função de proferir decisões no âmbito 
do Poder Judiciário vem causando grande preocupação principalmente no que se refere aos vieses algorítmicos.

Segundo Nunes (2018), a discursão a sobre vieses algorítmico repassa a questão de vieses cognitivos, pois parte do princípio que a ação humana é o ponto de partida para a resposta encontrada por uma máquina de inteligência artificial. Ou seja, as informações inseridas na máquina são selecionadas por uma pessoa que carrega suas concepções de mundo, seus valores e suas crenças.

"Os vieses (cognitivos) são, pois, falhas cognitivas geradas por um pensar tendencioso, que desrespeita uma expectativa de imparcialidade" (ANDRADE, 2019, p. 519). Em outras palavras, os vieses cognitivos são erros de pensamentos inerentes a forma como é percebido, processado e interpretando as informações ao redor. São tendências que podem levar à desvio sistemático de lógica ou de racionalidade no julgamento.

Sabendo que, os vieses são inerentes ao pensamento humano, é possível admitir que os vieses podem ser transmitidos às máquinas por meio da compilação das informações que comporão a fonte das previsões ou dos resultados produzidos pela IA.

E em face de os vieses se apresentarem como uma característica intrínseca do pensar humano, pode-se concluir, de igual modo, que um algoritmo criado por seres humanos enviesados provavelmente padecerá do mesmo "mal", não de forma proposital, mas em decorrência das informações fornecidas ao sistema. (NUNES, 2018, p. 6)

Esse "mal" apontado por Nunes (2018) é chamado de vieses algorítmico, conceituado como sendo tendências que levam o algoritmo a cometer erros ou reproduzir conceitos preconcebidos. Esses erros são frequentemente resultados da base de dados injetada para servir de modelo para as representações feita pelos sistemas de IA. Um caso que demonstra como os vieses algorítmicos pode produzir resultados preconceituosos é abordado por um estudo feito por pesquisadores da Universidade da Virgínia, Estados Unidos, que mostram como os algoritmos treinados com duas bases de dados composta por fotos de pessoas nas mais variadas situações, classificava como mulheres, pessoas do sexo masculino quando fotografados fazendo alguma atividade doméstica. (VIEIRA, 2020)

\begin{abstract}
Alguns pesquisadores têm argumentado que algoritmos de aprendizagem de máquina podem abordar vieses sistêmicos projetando modelos "neutros" que não levam em conta variáveis sensíveis como. Mas embora possa parecer possível em situações hipotéticas, não parece ser o caso na vida real. (BABO, 2020)
\end{abstract}

Na seara jurídica, o caso mais emblemático de vieses algorítmicos, com certeza refere-se ao COMPAS, (Correctional Offender Management Profiling for Alternative 
Sanctions), um software adotado por alguns entes federativos dos Estados Unidos, que determina um índice de reincidência dos detentos do sistema prisional.

O Compas utiliza um questionário, que a partir dele é quantificado um score de um a dez. Um corresponde a probabilidade muito baixa de o detento cometer outros crimes e dez se refere a uma alta probabilidade de o criminoso voltar a cometer delitos e ser preso novamente. Essa pontuação é considerada pelos juízes na tomada de decisões para concessão ou não de certos benefícios como: habeas corpus, liberdade condicional, progressão de pena.

A partir de uma análise feita do Compas, pela ProPublica, um jornal investigativo de New York, percebeu-se que os detentos negros têm maior probabilidade de receberem uma pontuação alta, identificando que eles são mais propensos a ser presos novamente (MAYBIN, 2016). A investigação "revelou que, ao passarem pelo crivo do Compas, acusados negros têm $77 \%$ mais probabilidade de serem classificados como possíveis reincidentes do que acusados brancos [...]" (PIERRO, 2018).

A veiculação desse resultado suscitou discussões a respeito dos critérios adotados pelos algoritmos para a determinação dos seus resultados. Critérios esses, muitas vezes, protegidos por seus criadores e resguardados pelas normas de proteção intelectual. Essa invisibilidade no processo de decisão pelos algoritmos pode acarretar na impossibilidade ao acesso à direitos como o contraditório e ampla defesa.

A ausência de transparência nos critérios utilizados pelo algoritmo, é potencialmente grave em uma outra ótica, qual seja: como se defender de um posicionamento que não se sabe como foi construído? Em um julgamento, no estado Wisconsin, nos Estados Unidos, o juiz proferiu sua sentença levando em consideração o alto índice de reincidência do réu, Eric Lomes. O índice foi calculado pelo sistema Compas. Sentenciado em 11 anos de prisão, Lomes recorreu à justiça alegando que não teve acesso as fórmulas matemáticas adotadas pelo software e, por isso, não podia se defender de forma adequada. O recurso foi rejeitado pela Suprema Corte e a condenação continuou válida (AZEVEDO, 2019).

Sobre esse novo panorama que se forma com a implementação da tecnologia no âmbito das decisões judiciais, Oliveira faz duras críticas.

Nesse cenário, sistemas se automatizam e tomam decisões morais, sem, contudo, que estas relações estejam suficientemente explicadas ou refletidas. Isto sem mencionar os dilemas éticos que se entrecruzam a todo momento, quer dizer, então, que manifestações de injustiças podem ser perpetuadas de modo acrítico e autômato (OLIVEIRA,2019). 
No Brasil, o debate sobre a opacidade dos algoritmos teve palco após a implementação de um software no Poder Judiciário, com a função de sortear processos do Supremo Tribunal Federal. Em 2017, esse sistema foi o responsável por distribuir processos relativos à Operação Lava à Jato, o que gerou polêmica sobre a falta de transparência dos procedimentos utilizados pelo sistema. Para resolver as querelas referentes ao sistema e obedecendo ao regimento interno do SFT que diz "o sistema informatizado de distribuição automática e aleatória de processos é público, e seus dados são acessíveis aos interessados", em 2019 foi permitido uma auditoria externa por pesquisadores da UnB, a qual identificou fragilidades no sistema.

\begin{abstract}
Além disso, o parecer (da UnB) informa que modelo de distribuição individual dos processos fragiliza o sistema, à medida que o torna mais suscetível a manipulação no resultado do sorteio. Existem mecanismos de compensação para tornar a distribuição dos processos igualitária, contudo, envolve um conjunto de variáveis que complexificam ainda mais a questão (OLIVEIRA, 2019).
\end{abstract}

Os critérios utilizados pelos algoritmos devem estar disponíveis para todos, principalmente aqueles que direta ou indiretamente são afetados por seus resultados. Como recomenda o Parlamento Europeu, ao postular os princípios éticos da robótica na área jurídica. Disserta que os robôs deveriam ter uma espécie de "caixa preta” onde seja possível arquivar todos os procedimentos e todos os critérios adotados pela máquina para subsidiar suas decisões. Assim, quando questionados, poderia acessar seus registros e encontrar uma resposta lógica.

Retornando as proposições acerca dos viesses, é possível concluir que estes são inerentes a todos os seres humanos, sendo possível a criação de máquinas com inteligência artificial com os mesmos desvios de pensamentos. Dessa forma, caberia dizer que decisões enviesadas podem ser tomadas tanto por máquinas, quanto por pessoas. O que não impactaria em nada a inserção das máquinas com função decisória. Contudo, no âmbito do Poder Judiciário, há um critério de diferenciação, que se constitui como uma ferramenta que dificulta as tomadas de decisões imparciais. A fundamentação das decisões judiciais é um princípio constitucional, o qual exige que todas as decisões proferidas no curso de uma ação judicial devam ter seus fundamentos aludidos e devem ser calcados segundo as normas legais. Esse tópico será melhor elucidado na próxima seção.

\title{
3 FUNDAMENTAÇÃO DAS DECISÕES E A INTELIGÊNCIA ARTIFICIAL
}


A ideia de programar máquinas que utilizam sistemas de inteligência artificial no campo do Judiciário, tende a ser bem recepcionada em países que acumulam grandes quantidades de processos judiciais.

\begin{abstract}
Ocorre que o uso desses algoritmos e dessas ferramentas no ambiente jurídico se configura como uma tendência irreversível, notadamente diante da realidade envolta à prestação da atividade jurisdicional brasileira, considerando-se o atual estoque de aproximadamente 100 milhões de processos em curso, cujo número expressivo dá azo ao acolhimento de toda e qualquer técnica ou tecnologia que prometa reduzir o acervo de casos a serem decididos (NUNES E VIANA, 2018).
\end{abstract}

Para os autores, o que provoca o encanto pelas máquinas com inteligência artificial por parte dos agentes do direito e da justiça é a possibilidade de conjugar características humanas com elementos próprios das máquinas, resultando assim em um trabalho muito mais eficiente realizado em tempo ínfimo.

No Brasil, já é possível identificar algumas iniciativas em prol da automatização das decisões judiciais. Um exemplo disso, é o projeto denominado Victor, desenvolvido pelo Supremo Tribunal Federal com parceria da Universidade de Brasília. O sistema está em atuação desde 2018.

Numa primeira etapa, o objetivo é que o Victor leia os recursos extraordinários apresentados, faça a vinculação de seu conteúdo com os temas de repercussão geral, tudo isto numa velocidade extraordinariamente superior. Vale dizer, nesses casos o Victor já sugere a decisão a ser tomada (LEONARDO, ESTEVÃO, 2020, p. 8).

Contrariando o que foi dito pelo STF ao anunciar a instalação do sistema de inteligência artificial. Segundo o tribunal, "a máquina não decide, não julga, isso é atividade humana". Entretanto, a identificação de recursos extraordinários que são vinculados a determinados temas repercussão geral, tem caráter decisório.

Uma iniciativa parecida foi realizada no Judiciário de Pernambuco com a implantação do sistema de inteligência artificial batizado de Elis. O sistema faz o reconhecimento de ações de execução fiscal e classifica qual delas está de acordo com as regras do direito processual e qual delas já prescreveu. O juiz José Faustino Macêdo, da vara de execuções fiscais da capital de Pernambuco, considera que, de certa forma, Elis decide, pois é o programa que diz se o processo está tudo ok ou não. O juiz ressalta que se não fosse necessário logar o sistema e verificar a decisão proferida, era possível que ele mesmo fosse substituído por completo pela máquina de inteligência artificial (Folha De São Paulo, 2020).

$\mathrm{Na}$ China, os avanços da tecnologia também já deram ensejo para a criação de sistemas que ajudam a decidir sentenças de prisão. O programa de computador foi 
desenvolvido para garantir decisões padronizadas, tendo como objetivo identificar padrões de distinção em diferentes casos de um mesmo crime. O programa abrange mais de 100 tipos de crimes, tais como: roubo, estupro e violação de segurança do estado. Os defensores do programa afirmam que será um mecanismo que deve evitar o abuso de poder, corrupção e treinamento insuficiente por parte dos juízes. Mas, por parte de alguns setores da sociedade, a instalação desse tipo de sistema se configura como "preguiça do Judiciário" e afirmam que as máquinas não reduzirão a corrupção na justiça do país (G1, 2006).

Todavia, a inserção cada vez mais rápida de tecnologias de inteligência artificial e todos os dilemas já aludidos no decurso desse estudo sobre os vieses algorítmicos e a falta de transparência dos procedimentos utilizados por esse tipo de ferramenta vai de encontro com o princípio da fundamentação das decisões judiciais.

(...) a necessidade de motivação das decisões judiciais adquiriu, a partir do século XVIII, status de obrigatoriedade no ordenamento jurídico de diversos países e, posteriormente, status de preceito fundamental insculpido em muitas constituições, inclusive na Constituição do Brasil, país no qual a motivação das decisões judiciais é uma garantia constitucional e um direito fundamental do cidadão (GILLET; PORTELA, 2018, p. 153).

No constitucionalismo pátrio, o preceito da fundamentação das decisões judiciais está esculpido no artigo $\mathrm{N}^{\circ} 93$ da Constituição Federal, onde prega que: "todos os julgamentos dos órgãos do Poder Judiciário serão públicos, e fundamentados todas as decisões, sob pena de nulidade" (BRASIL, 1988). Sendo assim, a Constituição determina que as decisões judiciais tenham fundamento válido e acessível às partes envolvidas, não sendo atendidos esses critérios, a decisão pode ser declarada nula.

Cella, Oliveira e Boff (2018), destacam que, nesse único artigo são comungados dois princípios constitucionais o princípio da publicidade e o das decisões fundamentadas, princípios esses que viabilizam o contraditório e a ampla defesa assim como o devido processo legal.

Todas as espécies de decisões judiciais devem ser, por força constitucional, motivadas, ou seja, devem expressar os motivos de fato e de direito que levarão ao convencimento do magistrado. O juiz, no exercício de suas funções, é obrigado a julgar os casos que são submetidos à sua jurisdição, sendo que na realização dessa tarefa deve, portanto, motivar suas sentenças por meio da exposição dos argumentos que o fizeram chegar à conclusão (GILLET E PORTELA p. 157).

A observância da garantia constitucional da motivação das decisões judiciais, emerge uma emblemática questão: é possível que as máquinas de IA, inseridas no campo das decisões judiciais, tenham a capacidade de argumentar suas decisões perante as partes envolvidas e ao 
público em geral? Como já foram pautados anteriormente, os casos de deliberação por parte de equipamentos tecnológicos vêm levantando discussões acerca da falta de transparência dos procedimentos utilizados para a construção dos seus resultados.

No âmbito do Código do Processo Civil (CPC), são abordados três elementos fundamentais, que devem ser obedecidos em conjunto pelo magistrado no exercício de sua função.

I - O relatório, que conterá os nomes das partes, a identificação do caso, com a suma do pedido e da contestação, e o registro das principais ocorrências havidas no andamento do processo;

II - Os fundamentos, em que o juiz analisará as questões de fato e de direito;

III - o dispositivo, em que o juiz resolverá as questões principais que as partes the submeterem (BRASIL, 2015).

É a observância desses três elementos que compõem a decisão judicial, a falta de qualquer um deles, pode dar ensejo para a nulidade da decisão judicial. De forma que, todas elas são de essencial para o processo de tomada de decisão no curso de todo o processo. Não sem razão, Gillet e Portela (2018), ressaltam que a exposição dos motivos que levam as decisões proferidas, tem um peso maior, pois é dele que sustenta o princípio da segurança jurídica, princípio elementar da Constituição Cidadã.

As leis infraconstitucionais que tratam sobre o processo penal e processo civil, elencam as mesmas possibilidades que tornam as decisões judiciais não fundamentadas. No Código de Processo Civil está localizada no $\S 1^{\circ}$ do artigo 489 e no Código do Processo Penal, no $\S 2$ do artigo ${ }^{\circ} 315$. Dessa forma, não serão tidas como motivadas as decisões que:

\begin{abstract}
limitar-se à indicação, à reprodução ou à paráfrase de ato normativo, sem explicar sua relação com a causa ou a questão decidida; empregar conceitos jurídicos indeterminados, sem explicar o motivo concreto de sua incidência no caso; invocar motivos que se prestariam a justificar qualquer outra decisão; não enfrentar todos os argumentos deduzidos no processo capazes de, em tese, infirmar a conclusão adotada pelo julgador; limitar-se a invocar precedente ou enunciado de súmula, sem identificar seus fundamentos determinantes nem demonstrar que o caso sob julgamento se ajusta àqueles fundamentos; Deixar de seguir enunciado de súmula, jurisprudência ou precedente invocado pela parte, sem demonstrar a existência de distinção no caso em julgamento ou a superação do entendimento (BRASIL, 2015).
\end{abstract}

Portanto, é inquestionável que a fundamentação das decisões proferidas no percurso de um processo judicial deve ser calcada em argumentos sólidos e concisos, em que provenham das provas levantadas. Em um outro ponto de vista, pode se dizer que motivar uma decisão é:

justificar as razões pelas quais foram adotados determinados critérios de convicção que levaram o intérprete à aplicação de uma norma e o afastamento de outra, enunciando que fizeram parte de seu raciocínio jurídico e que serviram de sustentáculo para a sua decisão (GILLET E PORTELA, p. 158). 
A motivação das decisões, se faz ainda mais essencial em casos de aparente conflito de normas e quando há afastamento de um precedente. Ou seja, todas as vezes que a compreensão plena de todas as particularidades do caso requerer uma interpretação complexa, por causa de uma divergência entre normas, em que cabe ao magistrado escolher uma em detrimento de outra, seja por princípio ou por regra, as modificações devem ser claramente justificadas. Weber (2008) ressaltar que a fundamentação deve ser realizada por meio da força da argumentação que leve ao convencimento do auditório universal, pois conflito de normas não faz parte da seara da discricionariedade dos juízes. Os magistrados deverão escolher pela norma que tiver argumentos necessários para sua aplicação, visto que farão parte da motivação das decisões judiciais.

Nesse contexto, é possível concluir que as atribuições de um juiz demandam um alto grau de raciocínio e de cognição, que por mais próximo que possa assemelhar da capacidade humana de raciocínio, ainda assim a "efetiva prolação de pronunciamentos torna-se imperativa a compreensão de nosso sistema cognitivo de decisões, inclusive mediante e percepção dos vieses cognitivos humanos e algorítmicos" (NUNES; VIANA, 2018).

Uma decisão judicial emanada de uma máquina poderia satisfazer os anseios dos adeptos de uma eficiência a qualquer custo e daqueles que propalam, acima de tudo, a segurança jurídica e isonomia entre litigantes, tendo em vista a impressionante habilidade de cálculo e suposta neutralidade da mesma, sendo a IA vista como técnica de implementação de uma exatidão nunca vista e alcançada (NUNES; VIANA, 2018)

Contudo, lembram os autores, os vieses algorítmicos devem ser combatidos, sendo forçosa a criação de instrumentos regulamentários de defesa a transparência algorítmica dos procedimentos e dos resultados, além de ser necessário pôr em cheque a crença que o trabalho realizado por essas ferramentas seja sempre melhor do que o desenvolvido por seres humanos.

Nessa configuração enviesada e conflituosa, (pres)suponho que dificilmente as IAs em disputas serão capazes de enxergar umas às outras. Muito menos, aparentemente, poderão interpretar e entender os elementos implícitos e/ou os significados e sentidos "por trás" de determinadas "escolhas" dentre as possibilidades da hermenêutica jurídica e dos jogos discursivos que encobrem os interesses e demarcações de poder. Nem sequer me soa que seja possível ativar algum modo de reflexão ou autocrítica, a ponto de propiciar a revisão da tomada de decisão, com alteração de significados e sentidos - a intervenção humana não o fará, pois isso é raridade no meio das profissões jurídicas. Além disso, tudo aquilo que fugir ao padrão será considerado como "anomalia" na equação, no algoritmo, de sorte que pode existir algumas dificuldades em como lidar com essas situações. (PESSOA, 2020, p. 52) 
Sob outra perspectiva, Câmara (2014) salienta que o princípio da fundamentação das decisões judiciais é o dispositivo que garante a participação da sociedade no controle da atividade jurisdicional, lhe conferindo a legitimidade.

O dever de fundamentar é do próprio julgador, não podendo ser afastado pela utilização de um algoritmo. Dessa forma, mesmo em casos extremos de decisões emitidas por uma máquina, a elaboração da fundamentação deve manifestar os motivos pelos quais levam o julgador a deferir tal conclusão. Seguindo o mesmo entendimento, Jordi Nieva Fenoll ressalta a razão que sustenta a impossibilidade de uma máquina fazer a fundamentação de suas escolhas.

\begin{abstract}
Assim, embora tenham sido feitas tentativas para avançar neste terreno, as ferramentas de inteligência artificial de debate jurídico, ou não, não vão além da sugestão, porque são incapazes de proceder a essa ponderação, tão difícil também para o ser humano. Porém o juiz possui ao menos a defesa da motivação, que leva em conta armas da retórica que dificilmente pode utilizar de maneira completamente oportuna uma máquina (FENOLL, 2018, p 116)
\end{abstract}

Por isso, a responsabilidade de fundamentar, se caracteriza como, eminentemente, de caráter humano, não sendo possível delegar essa função a sistemas de inteligência artificial.

\title{
4 CONSIDERAÇÕES FINAIS
}

A inserção cada vez mais rápida dos recursos de inteligência artificial no direito é um movimento irrefreável, assim como em outras áreas da vida humana. Contudo, é imprescindível que as máquinas atuem de forma complementar ao trabalho humano e não numa perspectiva de substituição. Nesse ponto de vista, as considerações de Pugliese e Brandão (2015), concernentes ao uso dos algoritmos, os autores dissertam "assim como podem haver acertos, as informações geradas podem ser inúteis para a situação dada" (2015, p. 140). Ou seja, não se trata de um método inquestionável, que trabalha com total imparcialidade. Por isso, aquele que procura a ajuda das máquinas para tomar decisão deve ter em mente que os resultados, dados e informações geradas não falam por si, que só depois de passar pela racionalidade humana é que eles ganham sentido "o sentido não é dado, nem mesmo em um dado - é sempre construído” (Pugliese; Brandão, 2015, p. 140).

Dessa forma, é plenamente aceitável a utilização de máquinas no Judiciário, quando essas têm função meramente burocrática, em trabalhos dispendiosos e repetitivos, mesmo sob a supervisão de uma pessoa. $\mathrm{O}$ problema reside nos casos em que inteligência artificial é desenvolvida para exercer a tarefa de demandar decisões. 
Ao longo do estudo foi possível demarcar que o uso acrítico desses instrumentos com função total ou parcial de decidir pode incorrer em replicação de preconceitos e discriminações que estão presentes na sociedade, por meio dos vieses algorítmicos. Esse fato somado à opacidade dos algoritmos, inacessível ao entendimento da maior parte das pessoas, torna-se um cenário perigoso ao exercício da cidadania, pois impossibilita o alcance a direitos como o caso do contraditório e ampla defesa.

Para tornar as decisões judiciais o mais imparcial possível foi criado o princípio da fundamentação das decisões judiciais, o qual estabelece que, todas as decisões enunciadas ao longo de uma ação judicial sejam fundamentadas, ou seja, é imperioso que haja a exposição dos motivos que respaldem as deliberações pelos agentes da justiça. Esse princípio não é anulado quando a decisão parte de um equipamento de inteligência artificial, muito pelo contrário, é necessário que se tenha conhecimento acerca dos procedimentos que levaram o algoritmo chegar no resultado final. Embora existam posições que afirmam que uma máquina jamais poderá fundamentar suas decisões de tal forma como faz uma pessoa.

Isso posto, conclui-se que a inteligência artificial não pode ocupar todas as funções exigíveis em uma decisão judicial, pois os exemplos que se apresentam demostram que, reiteradamente, esses equipamentos vêm demostrando que podem repetir critérios subjetivos de seus criadores através dos vieses algorítmicos. Dessa forma, ainda se faz necessário o discernimento humano na competência de jugar, não cabendo, nessa função, a inteligência artificial. 


\section{REFERÊNCIAS}

ALPAYDIN, E. Introduction to Machine Learning. 3. ed. Massachusetts, MIT Press: [s.n.], 2014.

ANDRADE, Flávio da Silva. A tomada da decisão judicial criminal à luz da psicologia: heurísticas e vieses cognitivos. Rev. Bras. de Direito Processual Penal, Porto Alegre, vol. 5, n. 1, p. 507-540, jan.-abr. 2019.

AZEVEDO, Bernardo de. Sistema de inteligência artificial nos EUA prevê o "índice de reincidência" dos acusados. Bernardo de Azevedo e Souza. Direito Inovações e Novas Tecnologias. 2019. Disponível em https://bernardodeazevedo.com/conteudos/sistema-deinteligencia-artificial-nos-eua-preve/. Acesso em 04 março de 2021.

BABO, Gustavo Schainberg S. Discriminação Algorítmica: Origens, Conceitos e Perspectivas Regulatórias (Parte 1). Disponível em: https://www.dtibr.com/post/discrimina\%C3\%A7\%C3\%A3o-algor\%C3\%ADtmica-origensconceitos-e-perspectivas-regulat $\% \mathrm{C} 3 \% \mathrm{~B} 3$ rias-parte-

1\#: :text=Os\%20problemas\%20da\%20discrimina\%C3\%A7\%C3\%A3o\%20algor\%C3\%ADt mica,diversos\%20preconceitos\%20institucionais\%20da\%20so. Acesso: 13 de Março de 2021.

BRASIL. Constituição (1988). Constituição da República Federativa do Brasil de 1988. Brasília, DF: Presidência da República, 1988. Disponível em:

http://www.planalto.gov.br/ccivil_03/constituicao/constituicao.htm. Acesso em: 2 de março de 2021.

BRASIL. decreto lei no 3.689, de 03 de outubro de 1941. Código de Processo Penal.

Disponível em: http://www.planalto.gov.br/CCIVIL/Decreto-Lei/Del3689.htm.

BRASIL. Lei no 13.105 de 16 de março de 2015. Código de Processo Civil. Brasília, Disponível em: http://www.planalto.gov.br/ccivil_03/_ato2015-2018/2015/lei/113105.htm. Acesso: 17 de março 2021.

CÂMARA, Alexandre Freitas. Lições de direito processual civil: volume 1. 25. ed. São Paulo: Atlas, 2014. p. 64- 65.

CELLA, José Renato Gaziero; BOFF, Salete Oro; OLIVEIRA Júlia Francieli Neves de. Direito, governança e novas tecnologias II - Florianópolis: CONPEDI, 2018.

Computador decide sentença judicial na China. G1, Portal de notícias da Globo 13 de set. 2016. Disponível em: http://g1.globo.com/Noticias/Tecnologia/0,,AA1270740-6174,00COMPUTADOR+DECIDE+SENTENCA+JUDICIAL+NA+CHINA.html. Acesso em: 05 de março de 2021.

Dra Luzia, primeira robô-advogada do Brasil, já tem trabalho pela frente. Canal tech. Por redação, 05 de jul. 2017. Disponível em: https://canaltech.com.br/robotica/dra-luzia-primeirarobo-advogada-do-brasil-ja-tem-sua-primeira-missao-96658/. Acesso em: 12 de março de 2021. 
ELIAS, Paulo Sá. Algoritmos e inteligência artificial exigem atenção do Direito. Revista CONJUR. 20 de novembro de 2017. Disponível em: https://www.conjur.com.br/2017-nov20/paulo-sa-elias-inteligencia-artificial-requer-atencao-direito. Acesso: 13 de março de 2021.

FENOLL, Jordi Nieva. Inteligência artificial y proceso judicial. Marcial Pons: Madrid, 2018. $166 \mathrm{p}$.

FERNANDES, Anita Maria da Rocha. Inteligência artificial. Noções Gerais. VISUAL BOOKS, 2003. p. 07.

GILLET, Sérgio Augusto da Costa; PORTELA, Vinícius José Rockenbach Breves conexões entre a motivação das decisões judiciais e o campo da inteligência artificial. Cadernos de Direito, Piracicaba, v. 18(34): 153-171, jan.-jun. 2018 • ISSN Eletrônico: 2238-1228.

LEONARDO, César Augusto Luiz; ESTEVÃO, Roberto da Freiria. Inteligência artificial, motivação das decisões, hermenêutica e interpretação: alguns questionamentos a respeito da inteligência artificial aplicada ao direito. Revista Em Tempo, [S.1.], v. 20, n. 1, nov. 2020. ISSN 1984-7858. Disponível em: 〈https://revista.univem.edu.br/emtempo/article/view/3305>. Acesso em: 17 mar. 2021.

LOEVINGER, L. Jurimetrics: The Next Step Forward. Minnesotta. Law Review, v. 33, 1948.

MATEUS; Flora Mello Quintão, MENDONÇA Mariana de Carvalho. Machine learning na melhoria de processos internos: estudos de caso na indústria de varejo brasileira. Monografia (Engenharia de Produção) -Universidade Federal do Rio de Janeiro. Belo Horizonte. Disponível em:

http://monografias.poli.ufrj.br/monografias/monopoli10031889.pdf. Acesso em 11 de março de 2021

MAYBIN, S. Sistema de algoritmo que determina pena de condenados cria polêmica nos EUA. BBC News, São Paulo, out. 2016. Disponível em:<http://www.bbc.com/portuguese/brasil-37677421>. Acesso: 15 março 2021.

MEDEIROS; Nathália Roberta Fett Viana de. Uso da inteligência artificial no processo de tomada de decisões jurisdicionais: Uma análise sob a perspectiva da teoria normativa da comparticipação. Belo Horizonte, 2019. Disponível em:

http://www.biblioteca.pucminas.br/teses/Direito MedeirosNRFV 1.pdf. Acesso: 17 de março de 2021

MELO, Jairo. Tribunal de Justiça do Distrito Federal. 2020. Inteligência artificial: uma realidade no Poder Judiciário. Disponível em:

https://www.tjdft.jus.br/institucional/imprensa/artigos-discursoseentrevistas/artigos/2020/inteligencia-artificialAcesso em: 10 de março de 2021.

NUNES, Dierle; VIANA, Aurélio. Deslocar função estritamente decisória para máquinas é muito perigoso. Revista CONJUR. 2018. Disponível em: https://www.conjur.com.br/2018jan-22/opiniao-deslocar-funcao-decisoria maquinas-perigoso\#sdfootnote9anc. Acesso em: 03 de março de 2021

NUNES. Dierle; MARQUES, Ana Luiza Coelho. Inteligência Artificial e Direito Processual: Vieses Algorítmicos e os riscos de atribuição de função decisória às máquinas, Disponível em:https://www.academia.edu/38112588/Intelig\%C3\%AAncia_artificial_e_direito_processua 
1_vieses_algor\%C3\%ADtmicos_e_os_ricos_de_atribui\%C3\% A7\%C3\%A3o_de_fun\%C3\%A 7\%C3\%A3o_decis\%C3\%B3ria_\%C3\%A0s_m\%C3\%A1quinas. Acesso em 29 de Fevereiro de 2021.

OLIVEIRA, Wagner Vinicius. Distribuição dos processos: o algoritmo sob suspeita.

JUSTIFICANDO mentes inquietas pensam direito. 2019 Disponível em

http://www.justificando.com/2019/04/10/distribuicao-dos-processos-o-algoritmo-sobsuspeita/Acesso: 15 de março de 2021.

PARLAMENTO EUROPEU. Resolução do Parlamento Europeu, de 16 de fevereiro de 2017, que contém recomendações à Comissão sobre disposições de Direito Civil sobre Robótica (2015/2103(INL)). Disponível em:

http://www.europarl.europa.eu/sides/getDoc.do?pubRef=-//EP//TEXT+TA+P8-TA-2017$0051+0+\mathrm{DOC}+$

$\mathrm{XML}+\mathrm{V} 0 / / \mathrm{PT}$. Acesso em15 de março de 2021.

PEIXOTO, Fabiano Hartmann; SILVA, Roberta Zumblick Martins da. Inteligência artificial e direito - 1.ed. Curitiba: Alteridade Editora, 2019

PEREIRA, Sebastião Tavares. Que é isto, a Enorma? Elementos para a teoria geral do Direito. In: BRANDÃO, Cláudio (org). Princípios do Processo em Meio-Reticular Eletrônico: fenomenologia, normatividade e aplicação prática. São Paulo: LTr, 2017

PESSOA; Daniel Alves. O uso de inteligências artificiais no sistema judicial brasileiro: cenário de disputas. PERIÓDICOS UNISUL. Julho a Dezembro 2020. 2020. Disponível em: http://www.portaldeperiodicos.unisul.br/. Acesso: 20 de Março de 2021.

PIERRO, Bruno. O mundo mediado por algoritmos. Sistemas lógicos que sustentam os programas de computador têm impacto crescente no cotidiano. Pesquisa FAPESP. Edição 266.abr. 2018. Disponível em: https://revistapesquisa.fapesp.br/o-mundo-mediado-poralgoritmos/. Acesso: 02 de março de 2021

PUGLIESI, Márcio; BRANDÃO, André Martins. Uma conjectura sobre as tecnologias de big data na prática jurídica - DOI: 10.12818/P.0304-2340.2015v67p453. REVISTA DA FACULDADE DE DIREITO DA UFMG, [S.1.], n. 67, p. 453-482, jun. 2016. ISSN 19841841. Disponível em:

<https://www.direito.ufmg.br/revista/index.php/revista/article/view/1731>. Acesso em: 05 março 2021.

ROCHA, Quithéria Maria de Souza; AMARO, Mylene Manfrinato Dos Reis. O desafio da unificação da inteligência artificial no Judiciário brasileiro. 2020. Belo Horizonte. Acesso em 10 de março de 2021. Disponível em: www.conpedi.org.br em publicações

RODAS, Sérgio. Algoritmos e IA são usados para que robôs decidam pequenas causas.

Revista CONJUR. Disponível em: <https://www.conjur.com.br/2019-out-27/algoritmos-iasao-usados-robos-decidam-pequenas-causas>. Acesso em: 13 mar. 2021.

SHALEV-SCHWARTZ, S.; BEN-DAVID, S. Understanding Machine Learning: From Theory to Algorithms. Cambridge: Cambridge University Press, 2014

VALENTINI, Romulo Soares. Julgamento por computadores? As novas possibilidades da juscibernética no século XXI e suas implicações para o futuro do direito e do trabalho 
dos juristas. Tese (Doutorado em direito) - Faculdade de Direito, Universidade Federal de Minas Gerais.2017. Belo Horizonte. Disponível em: https://as1 .trt3.jus.br/bdtrt3/bitstream/handle/11103/45082/VALENTINI\%2c\%20Romulo\%20Soares\%20$\% 20 \mathrm{Julgamento} \% 20$ por\%20 computadores.pdf?sequence=1\&isAllowed=y. acesso: 03 de março de 2021

VIEIRA, Carla. Inteligência Artificial e Vieses Algorítmicos. 2020. Loggi. Disponível em: https://partiu.loggi.com/intelig\%C3\%AAncia-artificial-e-vieses-algor\%C3\%ADtmicos992ee4786ca Acesso em: 10 de março de 2021

WEBER, Thadeu. Justiça e poder discricionário. Direito Fundamentais \& Justiça, Porto Alegre, v. 2, n. 2, jan./mar. 2008. Disponível em:

http://dfj.emnuvens.com.br/dfj/article/view/542. Acesso em: 20 de março de 2021. Acesso: 17 de março 2021 